\title{
Preface: Sensors for Advanced Manufacturing, Wearables, and Point-of-Care Devices in La Belle Labs at Arizona State University
}

KEY WORDS: point-of-care sensing, advanced manufacturing, wearable devices, electrochemical impedance spectroscopy, rapid prototyping, health monitoring

ABBREVIATIONS: EIS, electrochemical impedance spectroscopy; POC, point of care

\section{AIMS AND SCOPE}

Currently, Arizona State University (ASU) is home to more than 100,000 students at four campuses: West, Polytechnic, Main Campus in Tempe, and Phoenix Downtown. It hosts the largest engineering school in the country with over 22,000 students. ASU is a microcosm of Arizona in terms of diversity by just about every metric. It is a very representative place as well as an innovative academic institution.

We have assembled a very large laboratory (known as the La Belle Laboratories) at ASU, housed at two physical locations. There are often between 80 and 90 members in the laboratory working on problems outlined in this special issue. At one location is a 2,000-square-foot machine shop with modern manufacturing equipment from computer numeric controlled equipment, laser cutting, and 3D printing (from fused deposition modeling to stereolithography). At the other location is a wet lab space, comprising about 1,800 square feet of space with screen printing, enzyme-linked immunosorbent assay, and electrochemical stations, along with standard lab equipment.

\section{LA BELLE LABORATORY CORES}

\section{A. Advanced Manufacturing}

The Advanced Manufacturing team in La Belle Labs uses advances in manufacturing techniques to rapidly prototype for research. Our projects include development of innovative prosthetic technology using press-fit structures and mechanical principles, mechanical bladders for children, spine force sensors to help surgeons operate for scoliosis, an osseo-screw for bone fixation, and an invertible bed for patients with disabilities. We focus on solving real-world medical problems using a mix of old and new mechanisms, and prototyping solutions using 3D printers, laser cutters, indoor blacksmithing and welding stations, and a full machine shop. In this section of the special issue on sensors, we present three papers from the Advanced Manufacturing core. $^{1-3}$

\section{B. Wearables}

The Wearables team focuses on the development and testing of wearable devices. In recent years, these devices have become computationally intensive and are more prevalent. Also, they are becoming a serious player in the clinical space. Our goal is to develop a multisensor, flexible wearable device to be tested on patients. Current state-of-the-art devices are often inaccurate and uncomfortable to the user, and some do not collect continuous physiological data. The device developed in our laboratory is capable of continuous collection of ECG, temperature, and activity. It will be validated in a long-term, 30-day human subject trial. Future goals for the device include the integration of pulse oximetry, respiration rate, adhesive conductive sensors, galvanic skin response, blood pressure, and wireless data transfer. We foresee the wearable device having a major impact in the clinical space, as it will allow safe and accurate remote patient monitoring. Remote monitoring will increase patient quality of life and decrease incidence of hospital readmission, a problem costing the US healthcare system several hundreds of millions to billions of dollars annually. In this special issue, we present four papers from the Wearables core. $^{4-7}$ 


\section{Point-of-Care Biosensing}

Our laboratory is designing affordable and effective point-of-care biosensors. These range from noninvasive, such as the tear glucose sensor, to electrochemical impedance spectroscopy to detect multiple markers simultaneously. Each platform has made leaps of progress in the last few years. Noninvasive sensors have been funded by BioAccel, the Mayo Development Award, and Advanced Tear Diagnostics. We also have collaborations with facilities such as the Mayo Clinic and Tokyo University of Agriculture and Technology (Japan). A rapid, accurate, and low-cost platform capable of multimarker sensing is currently a large need. Our laboratory has implemented electrochemical impedance spectroscopy to detect various biomarkers using an "optimal binding frequency."

\section{Noninvasive Sensing}

Noninvasive POC biosensing has two major projects, tear glucose and saliva glucose. The tear project involves the use of tear fluid to measure various biomarkers and correlate their values with blood values. The saliva project uses saliva as the main detection medium to measure glucose for diabetes mellitus. In this special issue, we present seven papers from the Point-of-Care Biosensing core. ${ }^{9-13}$

\section{Multimarker Sensing}

The goal of the multimarker sensing project is the development of a rapid, label-free, and accurate platform sensing technology capable of multimarker detection. La Belle Labs intends to apply this platform to diabetes, cardiovascular disease, cancer, and organ transplant health, as well as trauma care. We have demonstrated, using our methods, that HDL/ LDL can be measured for cardiovascular health, and we are working on diabetes and trauma. ${ }^{8-13}$

Jeffrey T. La Belle is currently an Assistant Professor in the School of Biological Health and Systems Engineering and the Biodesign Institute at Arizona State University. He is a member of the National Academy of Inventors and holds adjunct status in Mechanical Engineering as well as the College of
Medicine at Mayo Clinic Arizona. He has a Ph.D. and an MS in Biomedical Engineering from ASU and an MS and a BS in Electrical Engineering from Western New England University in Springfield, Massachusetts. The La Belle Laboratories have been home to more than 200 undergraduate and graduate students across various engineering and nonengineering disciplines. These student researchers' accomplishments have led to over 120 disclosures, 30+ applications, 13 licensed and 8 awarded patents, 70 publications, and many conference proceedings.

Chi-En Lin is a Senior Biomedical Engineer at Medtronic. He completed his Ph.D. in Biomedical Engineering at Arizona State University in August 2018 under the mentorship of Dr. Jeffrey La Belle. He has conducted academic research with interdisciplinary teams while developing practical biosensors alongside industrial sponsors. He specializes in electrochemical biosensors for point-of-care diagnostics instrumentation. Many of the sensors developed by him and Dr. La Belle are suitable for diseases such as diabetes, cardiovascular diseases, cancer, and dry eye. He was awarded the U. Metrohm Young Chemist Award of 2018 for his outstanding contribution to translational science. During his Ph.D. studies, he authored 5 patent applications, 13 peer-reviewed publications, and 19 conference presentations.

\section{SUMMARY}

The papers presented in this special issue are the work of students who studied at the La Belle Laboratories. They include capstones, honor's thesis projects, and general projects carried out in the laboratory. The students who authored these works also designed and innovated the research presented here.

\section{REFERENCES}

1. Walsh A, Douglass K, La Belle JT. BODDEE BUDDEE: Evaluation of different foams and thermoplastics to develop a biofidelic manikin for cardiopulmonary resuscitation. Crit Rev Biomed Eng. 2019;47(2):101-8.

2. Wieser M, Liu J, Hernandez P, La Belle JT. A comparison of force sensing for applications in prosthetic haptic feedback. Crit Rev Biomed Eng. 2019;47(2):109-19. 
3. Conrad K, Choca J, Lathers S, La Belle JT. Staggered nitinol wire actuator array for high linear displacement and force-to-mass ratio. Crit Rev Biomed Eng. 2019; 47(2):121-9.

4. Chavez Gaxiola A, Fisher Z, La Belle J. Toward the development of a wearable optical respiratory sensor for real time use. Crit Rev Biomed Eng. 2019;47(2): 131-9.

5. Joshi AN, Nystrom AL, La Belle JT. Non-contact type pulse oximeter. Crit Rev Biomed Eng. 2019;47(2):141-51.

6. Mason C, Erlick B, La Belle JT. Proof of concept for a universal identification system for medical devices. Crit Rev Biomed Eng. 2019;47(2):153-8.

7. Uchimura KD, Adamson TL, Karaniuk KM, Spano ML, La Belle JT. Feasibility of commercially marketed health devices for potential clinical application. Crit Rev Biomed Eng. 2019;47(2):159-67.

8. Deng A, Matloff D, Lin CE, Probst DL, Broniak T, Alsuwailem M, Lin C-E, Probst D, Broniak T, La Belle J. Development toward a triple-marker biosensor for diagnosing cardiovascular disease. Crit Rev Biomed Eng. 2019;47(2):169-78.

\section{Guest Editors:}

Chi-En Lin, Ph.D.

School of Biological and Health Systems

Engineering

Arizona State University, Tempe

Jeffrey T. La Belle, Ph.D.

School of Medicine

Mayo Clinic Arizona, Scottsdale
9. Morrow B, Malkoc A, Gong T, Probst DL, Lin CE, Sen A, La Belle J. Development of electrochemical methods to enzymatically detect lactate and glucose using imaginary impedance for enhanced management of glycemic compromised patients. Crit Rev Biomed Eng. 2019;47(3):179-91.

10. Cardinell BA, Addington CP, Stabenfeldt SE, La Belle JT. Multi-biomarker detection following traumatic brain injury. Crit Rev Biomed Eng. 2019;47(3):193206.

11. Cardinell BA, Spano ML, La Belle JT. Toward a labelfree electrochemical impedance immunosensor design for quantifying cortisol in tears. Crit Rev Biomed Eng. 2019;47(3):207-15.

12. Honikel MM, La Belle JT. An experimental platform for characterizing cancer biomarkers with capabilities in noninvasive and continuous screening. Crit Rev Biomed Eng. 2019;47(3):217-34.

13. Khanwalker M, Jared J, Honikel MM, Smith V, Maxwell S, Santhanaraman S, La Belle, J. Electrochemical detection of fertility hormones. Crit Rev Biomed Eng. 2019;47(3):235-47. 
